\title{
smaRTI: Deploying the Internet of Things in Retail Supply Chains
}

\author{
smaRTI bringt das Internet der Dinge in die Supply Chain des Handels
}

\author{
Björn Anderseck \\ Alexander Hille \\ Fraunhofer Institute for Material Flow and Logistics IML, Dortmund
}

$\mathbf{T}$ his paper describes a cloud-based tracking and tracing system based on the principals of the Internet of Things. The 'Things' are returnable assets in retail supply chains. They are used to enhance the transparency over the whole supply chain, including redistribution processes, by making returnable assets smart through AutoID technologies. A cloud-based IT solution connects the supply chain partners and makes information visible where it is needed. The system is strictly developed with a user-friendly web interface, which is described in this paper.

D ieses Paper beschreibt ein Cloud-basiertes Tracking- und Tracing-System basierend auf dem Internet der Dinge. Die "Dinge" sind Mehrweg-Ladungsträger in Einzelhandels-Lieferketten. Sie werden genutzt, um die Transparenz in der gesamten Lieferkette zu erhöhen, einschließlich der Rücklieferprozesse, indem sie mittels AutoID-Technologien mit Intelligenz versehen werden. Die Cloud-basierte IT-Lösung verbindet die Partner der gesamten Lieferkette miteinander und macht alle Informationen dort sichtbar, wo sie benötigt werden. Dank eines Web-Interfaces bietet das System eine benutzerfreundliche Oberfläche. Dieses Web-Interface wird im Folgenden dargestellt.

[Keywords: smaRTI, Internet of Things, retail supply chains, goods, Internet der Dinge, Handel, AutoID, RFID]

\section{INTRODUCTION}

The Internet of Things (IoT) is deeply connected with Radio Frequency Identification (RFID). When Metro Group started its first RFID approach in 2004 [1], people expected huge benefits. Some have been realized, some not. The first approaches were based on item or case level tagging, which is the most difficult task in the retail sector. Main challenges are the vast varieties of objects and the reading performance problems in those cases.

From a logistics point of view the 'Thing' in a retail supply chain is the transport item. Today's retail supply chains are characterized by an extremely high variety of different transport items. These assets vary from simple plastic boxes up to reefer containers, which may have values up to 600 EUR. Today, in the context of sustainability, Returnable Transport Items (RTI) are becoming increasingly important in logistics.

In the case of RFID and the idea of the IoT RTIs can be used as physical objects that produce real-time data among the supply chain. A research project which deals with this subject is 'smaRTI' . This paper describes the background and objective of smaRTI to develop a cloudbased cross company system which combines individually identifiable RTIs with a real-time identification setup. The system allows every supply chain partner to gain benefit by using smart RTIs, in short: 'smaRTIs'. The described system is a running pilot in the consumer goods supply chain between CHEP (Pooling Provider), Mars (Consumer Goods) and REWE (Retailer).

\section{MOTIVATION}

The motivation to develop the described system is based on two major facts, which drive the development and research. The first fact is that the optimization of material flow is depending on the availability and transparency of a whole supply chain. Single processes in a company can be highly improved by information that is generated by other supply chain partners. A FMCG company (Fast Moving Consumer Goods) can improve its distribution by knowing the stocks in the supply chain at any time. However, the POS information (Point of Sale) is often held back by the retailers. Furthermore, the FMCG company is not only interested in sales figures, but also in stock data counted in assets or transport items. The second fact is that the use of RTIs enables not only the control of distribution but also the control of redistribution processes. Usually these two processes are controlled completely

\footnotetext{
${ }^{1}$ Details about smaRTI: http://www.smart-rti.de
} 
independently. Possible potentials by combining distribution and redistribution could not be lifted. Accordingly the RTI is used as the main identification object in the supply chain, including redistribution.

\section{Approach}

The basic principle is the use of RTI as the major information carrier over the whole supply chain. Considering the complete loop of RTIs, synergies become visible, as automatic control (self-control), transport optimization, and real-time transparency. With the aim to develop a practical solution for customers, the system has three outstanding characteristics that distinguish it from the today's market:

- Hybrid AutoID processes allow a customeroriented use of technologies. Hybrid stands for every AutoID technology that is able to read a unique ID stored in a combined printed label with clear text, a 1D and/or 2D barcode or a UHF Gen2 RFID transponder. With this combined hybrid identifier customers are able to use a high variety of hardware, e.g. computer terminals, smartphones, barcode scanners (1D/2D), RFID handhelds and gates, and UHF Gen2 compatible RTLS (Real Time Location Systems).

- Cloud-based repository establishes one single language for all supply chain partners. The socalled Master data can be individually extended by every partner, but the system itself ensures the consistency over the supply chain. Hardware devices, which generate the 'events', are connected to the rules data in real-time, which represents a working IoT showcase.

- Common standards and RTIs are essential for cross-company processes within the described system. It follows the EPC Standard (Electronic Product Code), a unique identification number for objects, by $\mathrm{GS}^{2}$, a global standardization company. By using EPCIS (EPC Information System) the events and interfaces are clearly described and the complete system is adaptable easily to common ERP or WMS systems. The RTIs are marked with a unique defined EPC, which is readable by every AutoID-system that understands EPC.

\section{SYSTEM DESCRIPTION}

The smaRTI-system is based on a Cloud Architecture. Figure 1 shows how the complete system in set up.

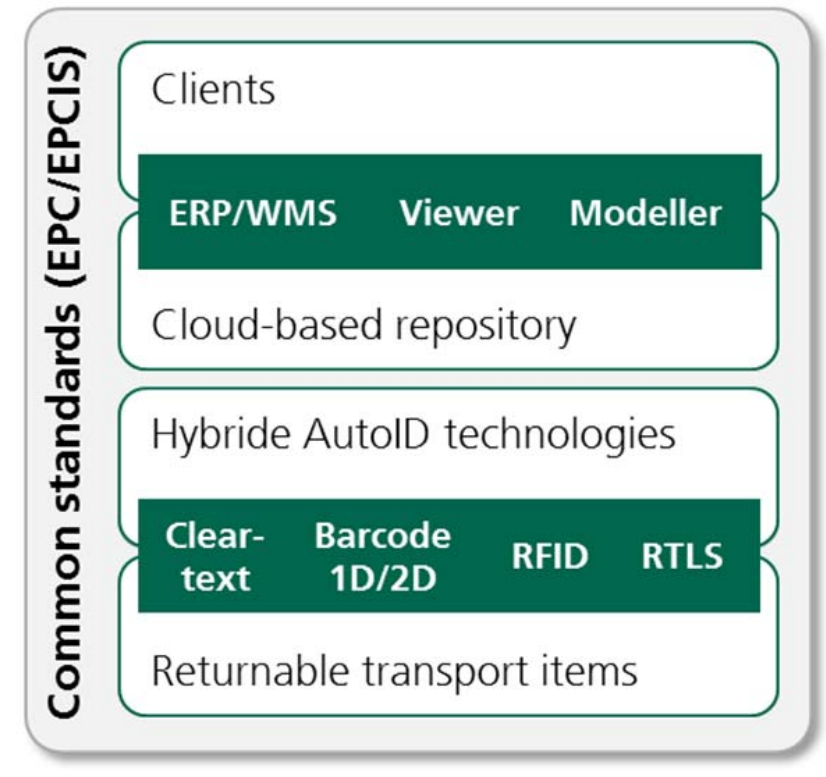

Figure 1.: $\quad$ System architecture

The RTIs are circulating the supply chain. At each information point the assets are identified by hybrid AutoIDtechnologies. These points are generating standardized events which are sent into the cloud-based repository. The customer who is generally one of the supply chain partners can access the data in several ways, e.g. over web applications. In the following sections the layers of the system will be described with more details.

\subsection{COMMON STANDARDS AND RTIS}

The smaRTI solution attends the data and logistics standards given by GS1. With EPCglobal, GS1 provides a unique identifier for every object, the EPC. These objects are separated in different numbering systems, e.g. company numbers, product numbers, or assets. The latter is essential for the described system. [2] The so-called Global Returnable Asset Identifier (GRAI) is a unique number for any returnable asset which is used in the industry sector. A GRAI is based on the Global Location Number (GLN), a unique number for companies, facilities, and their addresses.

Based on the EPC, the EPC Information Service (EPCIS) becomes an eminent system architecture for RFID integration. In the meantime EPCIS is also used in different branches, e.g. automotive [3], FMCG [4], and railway [5]. Even more, multiple architecture enhancements took place, software tools for hardware integration were developed and EPCIS supported supply chains were simulated in the context of research projects. The following examples show the impact of EPCIS and different approaches of existing projects and solutions.

2 Details about GS1 at http://www.gs1.com 
- AspireRFID middleware: The AspireRFID project is aimed at developing and promoting a free, open source, lightweight, standardcompliant, scalable, privacy-friendly, and integrated RFID middleware along with several tools to ease development, deployment and management of RFID-based applications. It implements several specifications from consortiums such as EPCglobal like EPCIS. Furthermore, AspireRFID provides a set of tools enabling RFID consultants to deploy RFID solutions without a need of low-level programming. [6]

- $\quad$ REST und EPCIS: In [7] a new approach for simplifying RFID application development and deployment is described. It shows how blueprints, which are successfully on the web like Cloud Computing and RESTful interfaces [8], can contribute to an easier adaption of RFID in already existing applications.

- EPCIS-based tracking and tracing of returnable transport items in the food supply: The main objective of this doctoral research is to apply the EPCIS standard for supporting the tracking and tracing process of intelligent containers in the food chain. A simulation model was also developed for simulating material flow of RTIs as well as their information flow namely the EPCIS events in the food supply chain [9]. This outstanding work has shown that EPCIS is a promising and also a branch overlapping approach for RFID-based tracking and tracing.

\subsection{Hybrid AutoID}

IoT use cases show a high variety of technologies, e.g. different barcodes, RFID, and sensor systems. A combination of these technologies makes it possible to add intelligence to objects. . Regarding the demand of logistics and different requirements of different branches and companies, the so-called hybrid AutoID-processes must be available [10]. In the framework of the smaRTI project, barcode handhelds were implemented at partners sites to scan a full load RTI, because it appears as a single unit. Where RTIs are always stacked and can be read in bulk RFID handhelds were implemented, e.g. at the pooling stock.

The project team implemented a supply chain solution based on a hybrid AutoID-RTI. The RTI has a human readable identifier, one barcode and a UHF Gen2 RFID transponder. The infrastructure consists of computer terminals, barcode handheld scanner, RFID handhelds, RFID gates and RFID-based RTLS.

The currently running pilot is applied to three different RTIs:
- CHEP wooden euro pallet: Common wooden pallet tagged with a RFID transponder and a barcode. The tag's position is confirming to the recommendation of GS1-Germany.

- CHEP Display pallet: A pallet used in a retail store for merchandising. It has two tags to ensure readability in every process step among the supply chain.

- REWE reefer trolleys: Trolleys that are used between distribution centers and stores. They are equipped with a combined barcode/RFID transponder.

Further types of RTIs will be integrated in the described pilot soon.

\subsection{Cloud-Based Repository}

It is proved that EPCIS is a promising and branch overlapping approach for RFID-based tracking and tracing systems. Also the development of cloud solutions, e.g. Software-as-a-Service (SaaS), is gaining in importance. The European Commission is expecting revenues of over 35 billion EUR in Europe in 2014 regarding Cloud Computing [11]. Furthermore the end-users' acceptance for these developments is increasing [12].

The described solution in the context of this paper represents a cloud-based EPCIS for RTIs. The cloud property is realized through the demand of the participating companies (REWE, Mars, CHEP) to keep software investments in their own IT landscape as low as possible. This is the major novelty of this solution. Common AutoID-systems are often used in combination with a local middleware for the control of RFID readers or barcode scanners. Each company in the supply chain using EPCIS has an own EPCIS repository which stores all EPCIS data. The data is received and can be queried over two interfaces. The cross linkage between the companies is realized by a high-level service called Discovery Service in combination with the Object Name Service (ONS) as an equivalent to Domain Name Service. Only the ONS and the Discovery Service are internet-based services in current EPCIS implementations.

Many end-users see the diversity of systems and landscapes of interfaces as a problem which implicates the following disadvantages:

- Discovery Service implementations are not standardized.

- Central instances are needed to setup and administrate a Discovery Service and Object Name Service.

- High costs for software and software adoptions (interfaces). 
- Complex processes for realizing supply chain wide systems.

The consequences are closed loop applications instead of open loop applications along the supply chain. In contrast to these facts, the smaRTI solution provides a high flexibility with extensive functionalities and avoids investment in new software. Cloudable EPCIS describes a new way of implementing an EPCIS. Thereby, the features repository, interfaces (capture and query), Discovery Service and ONS are realized as SaaS. Beside this, one main idea is to minimize the layer for the identification device connection which revolutionizes the middleware in an EPCIS. Figure 2 shows an overview of the new cloudbased architecture.

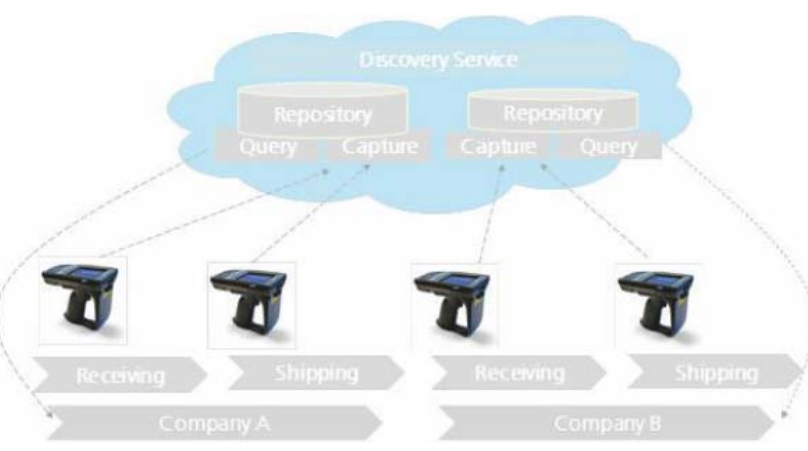

Figure 2.: $\quad$ Cloud-based EPCIS infrastructure

The data storage is in a cloud that very company has its own repository in. EPCIS events are generated by the AutoID devices, following the principals of the IoT: Available barcode or RFID handhelds provide enough capacities for generating XML telegrams, filtering and conversion of EPC data and calling web services. Also todays RFID readers are often equipped with modern microprocessors and virtual machines for running Java or C++ applications. The single end devices transfer EPCIS events over the world area network into the capture interface of the cloud. After that, the data is stored in the repository. The querying of events is done by the central Discovery Service. This service does not realize the classic functionality as described by EPCglobal as a mediator of query interface addresses for single repositories. In dependency to definable access rights on cross-company data, this service provides supply chain information in form of EPCIS events. The Discovery Service offers an enhanced form of the original query interface.

To generate EPCIS events on the identification devices, they must be enabled to 'talk' the EPCIS language. They have to know the object dispositions, business steps, read points and business locations. This logic for the devices is also available out of the cloud. Every user is able to define its own EPCIS language web-based. For that he creates his own master business vocabulary in form of business steps, dispositions, read points, etc. in simple forms. With a modeling tool, the EPCIS logic for the end devices must be defined. A screenshot of the EPCIS Logic Modeller is shown in Figure 3.

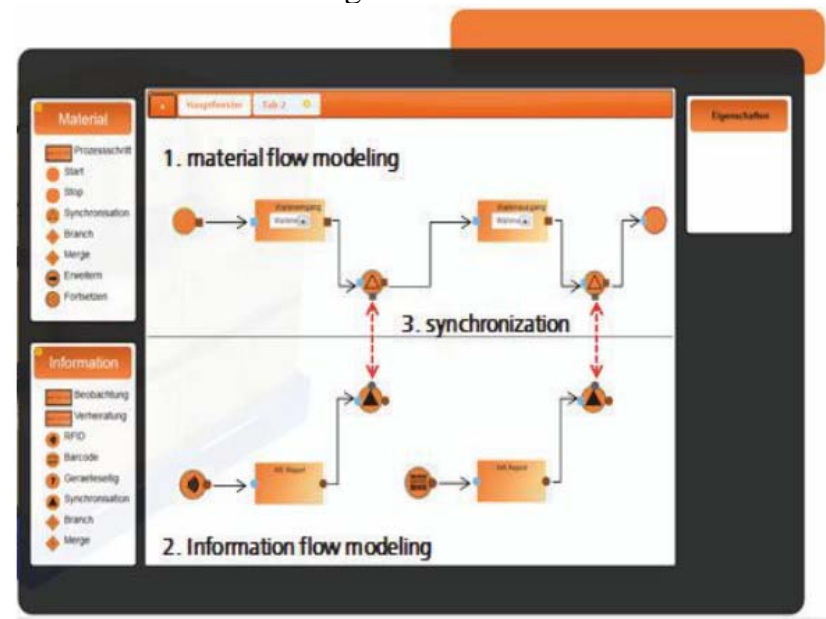

Figure 3.: $\quad$ EPCIS Logic Modeler

At the beginning the material flow has to be created and readpoints can be assigned for every process step. In the shape above the allocation of EPCIS reports are allocated to single process steps by a modeled synchronization. The existing software supports the release, observation and aggregation. In the event property field on the right hand side the additional master data can be assigned and identification hardware (barcode scanner, RFID reader) allocated. Additionally filtering or converting functions can be integrated. As the final step, every individual configuration gets stored in the cloud.

Needed software for the applied hardware devices is available as a download. Today, a very high variety of AutoID hardware is supported. The software is installed on the devices and is subsequently able to query the defined EPCIS logic and to generate EPCIS events after a scan or a read. Furthermore a dynamic adoption of the graphical user interface for example on the handheld is possible. The complete EPCIS logic is in the cloud and can be updated by the end-user.

\section{RESUlTS AND OPERATION}

The aim of the smaRTI project and the described system is to track and trace assets in a supply chain by using smart RTIs. With this approach benefits can be generated, especially by the integration of redistribution processes, as automated management of empty assets. The IoT is created by smart objects, the RTIs, which are able to control the material flow in combination with the cloud-based IT system. Three data standards are used and essential: to the EPC, the Serial Shipping Container Code (SSCC), and the GRAI. The system development is in deep cooperation with the retail supply chain partners. The adaption to other branches and supply chains is possible by using common 
standards. Thus, barriers which precluded companies from using smart RTIs in combination with AutoID technologies are eliminated, e.g. investments in software components. In the most simple form, a handheld scanner with internet connection is sufficient to use the system.

The running pilot ${ }^{3}$ shows new opportunities to the participants by using real-time data generated by the RTIs. The retailer REWE revolutionized the management of the redistribution from the stores to the distribution center. By using RTLS every single asset is trackable in real-time. The management of transports and orders can be automated and replace the need of manual counting. The smaRTI system will be completely developed in December 2013. After the successful realization of the IoT in the retail supply chain, further pilot implementations are scheduled.

\section{REFERENCES}

[1] Metro Group, "RFID: uncovering the value: Applying RFID within the Retail and Consumer Package Goods Value Chain”. Düsseldorf: METRO Group, 2004.

[2] GS1 Germany. (2012) Identifikation. [Online]. Available: http://www.gs1-germany.de/gs1standards/identifikation/

[3] Daimler AG. (2012) RAN - RFID Automotive Network. [Online]. Available: http://www.autoran.de/en/project.html

[4] Fraunhofer IML. (2012). [Online]. Available: http://www.smart-rti.de

[5] L. Andersson and G. Ivansson, "RFID in Rail," 2011.

[6] GS1 Aspire. (2012) AspireRFIDmiddleware. [Online]. Available: http://wiki.aspire.ow2.org

[7] D. Guinard, C. Floerkemeier, and S. Sarma, "Cloud computing, REST and Mashups to simplify RFID application development and deployment," in Proceedings of the Second International Workshop on Web of Things, ser. WoT ’11. ACM, 2011, pp. 9:1-9:6.

[8] D. Guinard, M. Mueller, and J. Pasquier-Rocha, "Giving RFID a REST: Building a Web-Enabled EPCIS,” in Internet of Things (IOT) 2010, 2010, pp. 1-8.

\footnotetext{
${ }^{3}$ Visualisation of the supply chain:

http://www.youtube.com/watch?v=2EKGAZDeXgg
}

[9] R. Wang, S. Prives, R. Fischer, M. Salfer, and W. Gunthner, "Data analysis and simulation of Auto-ID enabled food supply chains based on EPCIS standard," in Automation and Logistics (ICAL), 2011 IEEE International Conference on, title=Data analysis and simulation of Auto-ID enabled food supply chains based on EPCIS standard, 2011, pp. 58-63.

[10] B. Maettig, M. Fiedler, A. Hille, and B. Anderseck, "How AutoID Processes Shape the Internet of Things: The OpenID-Center Development Process," in The Impact of Virtual, Remote, and Real Logistics Labs, ser. Communications in Computer and Information Science, D. Uckelmann, B. Scholz-Reiter, I. R"ugge, B. Hong, and A. Rizzi, Eds. Springer Berlin Heidelberg, 2012, vol. 282, pp. 134-147.

[11] European Commission. (2011) Digital Agenda: Commission seeks views on how best to exploit cloud computing in Europe. [Online]. Available: http://europa.eu

[12] M. ten Hompel, M.-B. Meinhardt, and T. Lippmann, Cloud computing für Logistik: Akzeptanz und Nutzungsbereitschaft der Logistics Mall bei Anwendern und Anbietern: eine qualitative und quantitative empirische Analyse. Stuttgart: Fraunhofer Verlag, 2011.

M.Sc. Dipl.-Inf. Alexander Hille, born in 1984, studied Business Informatics at the University of Applied Science Dortmund and Electronic and Information Technology (extra-occupational) at the state-maintained distance teaching University Hagen. In 2007 he started working as a scientific assistant in the packaging and retail logistics department of the Fraunhofer Institute for Material Flow and Logistics IML in Dortmund. Since 2011 Alexander Hille is the head of the openID-center, a unique, open integration platform of over $1500 \mathrm{~m}^{2}$, where the logistics of the future gets conceived, tested and brought to life.

Dipl.-Wirt.-Ing. Björn Anderseck, born in 1982, studied Industrial Engineering at the Technical University Dortmund. Since 2008 he has been working as a scientific assistant in the packaging and retail logistics department of the Fraunhofer Institute for Material Flow and Logistics IML in Dortmund. Since 2011 Björn Anderseck is the head of AutoID-Technologies. His research focus are AIDC-Technologies (Automatic Identification and Data Capturing) especially in the field of smart transport items. 